\title{
New information on the early Permian lanthanosuchoid Feeserpeton oklahomensis based on Computed Tomography
}

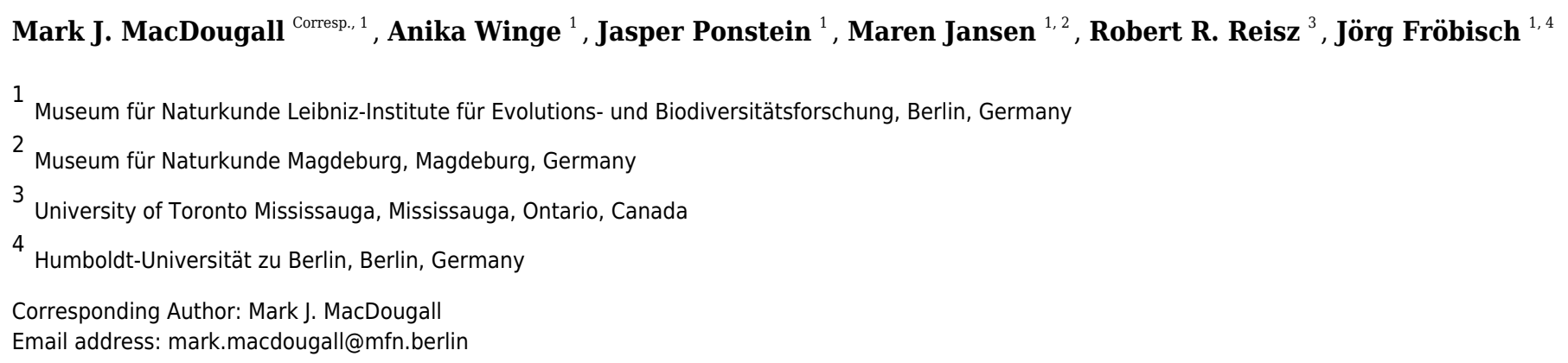

The cave deposits of the Lower Permian Richards Spur locality in Oklahoma, USA, have produced an incredible number of terrestrial tetrapod taxa, many of which are currently only known from this locality. One of the many recent taxa to be described from the locality was the small lanthanosuchoid parareptile Feeserpeton oklahomensis.

Represented by a well-preserved, near complete skull, F. oklahomensis would have been a small predatory reptile, likely preying upon arthropods, and contributes to the extensive tetrapod fauna that was present at Richards Spur. New computed tomography (CT) data of the holotype and only specimenhas allowed us to visualize and describe previously obscured and inaccessible anatomy of this taxon. These areas include the mandibular ramus, the palate, the sphenethmoid, the epipterygoids, and the braincase. Furthermore, this new anatomical information allowed formerly unknown character codings to be updated, thus we also performed new phylogenetic analyses that incorporated this new information. The results of these updated phylogenetic analyses are very similar to those of past studies, with F. oklahomensis being found as the sister taxon to all other lanthanosuchoids. 
1 New information on the early Permian lanthanosuchoid Feeserpeton oklahomensis based on Computed Tomography

Mark J. MacDougall ${ }^{1}$, Anika Winge ${ }^{1}$, Jasper Ponstein ${ }^{1}$, Maren Jansen ${ }^{1,2}$, Robert R. Reisz ${ }^{3}$, and Jörg Fröbisch ${ }^{1,4}$

${ }^{1}$ Museum für Naturkunde Leibniz-Institute für Evolutions- und Biodiversitätsforschung, Invalidenstraße 43, 10115 Berlin, Germany

${ }^{2}$ Museum für Naturkunde Magdeburg, Otto-von-Guericke-Straße 68-73, 39104 Magdeburg, 10 Germany

11 3University of Toronto Mississauga, 3359 Mississauga Rd., Mississauga, Ontario, L5L1C6, 12 Canada ${ }^{4}$ Humboldt-Universität zu Berlin, Invalidenstraße 42, 10115 Berlin, Germany

Corresponding Author:

Mark MacDougall

44 Museum für Naturkunde Leibniz-Institute für Evolutions- und Biodiversitätsforschung,

45 Invalidenstraße 43, 10115 Berlin, Germany

46 Email address: mark.macdougall@mfn.berlin 
49 Abstract

50

51 The cave deposits of the Lower Permian Richards Spur locality in Oklahoma, USA, have

52 produced an incredible number of terrestrial tetrapod taxa, many of which are currently only

53 known from this locality. One of the many recent taxa to be described from the locality was the

54 small lanthanosuchoid parareptile Feeserpeton oklahomensis. Represented by a well-preserved,

55 near complete skull, F. oklahomensis would have been a small predatory reptile, likely preying

56 upon arthropods, and contributes to the extensive tetrapod fauna that was present at Richards

57 Spur. New computed tomography (CT) data of the holotype and only specimen has allowed us to

58 visualize and describe previously obscured and inaccessible anatomy of this taxon. These areas

59 include the mandibular ramus, the palate, the sphenethmoid, the epipterygoids, and the braincase.

60 Furthermore, this new anatomical information allowed formerly unknown character codings to

61 be updated, thus we also performed new phylogenetic analyses that incorporated this new

62 information. The results of these updated phylogenetic analyses are very similar to those of past

63 studies, with F. oklahomensis being found as the sister taxon to all other lanthanosuchoids.

64

65 
66

67

68

69

70

71

72

73

74

75

76

77

78

79

80

81

82

83

84

85

86

87

88

\section{Introduction}

The Lower Permian (Cisuralian) Richards Spur locality of southwestern Oklahoma, represented by an extensive cave system, is known for its immense terrestrial tetrapod fauna (Sullivan \& Reisz, 1999; MacDougall et al., 2017b). Over the last few decades, more than 30 taxa have been described from the locality (MacDougall et al., 2017b), which includes various anamniote tetrapods, synapsids, and reptiles. Among these tetrapods are numerous parareptile taxa, specifically: Colobomycter pholeter Vaughn, 1958, Delorhynchus priscus Fox, 1962, Bolosaurus grandis Reisz et al., 2002, Microleter mckinzieorum Tsuji et al., 2010, Abyssomedon williamsi MacDougall and Reisz, 2014, Delorhynchus cifelli Reisz et al., 2014, and Colobomycter vaughni MacDougall et al., 2016. Most early Permian continental assemblages exhibit only a single parareptile taxon; Richards Spur is in stark contrast to this pattern, with eight parareptiles being known from the locality (MacDougall et al., 2017b), several of which belong to the clade Lanthanosuchoidea (Vaughn, 1958; Fox, 1962; Modesto, 1999; MacDougall \& Reisz, 2012; Reisz, MacDougall \& Modesto, 2014; MacDougall, Modesto \& Reisz, 2016). Lanthanosuchoidea is a small clade of reptiles that includes various early and middle Permian forms. Currently, all early Permian lanthanosuchoids are only known from North America, whereas as the middle Permian taxa are known only from Russia. There are also notable differences between the North American and Russian lanthanosuchoids. The early Permian North American taxa are considered to be small, fully-terrestrial, predatory taxa (Modesto, Scott \& Reisz, 2009; Haridy, MacDougall \& Reisz, 2017; MacDougall et al., 2017a), whereas the middle Permian Russian taxa are larger and considered to be semi-aquatic (Sennikov, 1996; Reisz, 1997; Verrière, Brocklehurst \& Fröbisch, 2016). Overall, this suggests that the clade could have potentially originated in western Laurasia and later dispersed to eastern 
89 Laurasia, though the lack of Russian early Permian strata makes this biogeographic hypothesis 90 difficult to test.

91 The lanthanosuchoid Feeserpeton oklahomensis is one of the most recently described 92 taxa from Richards Spur locality and is currently only known from its holotype (MacDougall \& 93 Reisz, 2012). It is represented by a small, nearly complete skull, and is characterized by several 94 enlarged maxillary teeth on the maxillae and dentaries, as well as large postorbitals and small 95 squamosals. In the initial description, MacDougall and Reisz (2012) largely described the visible 96 external anatomy of the skull, although CT data was used to examine the mandibular dentition.

97 However, they did not examine any other areas of the skull that were obscured or inaccessible, 98 which left some aspects of the anatomy of the skull unknown.

99 Herein, we describe the previously inaccessible anatomy of Feeserpeton oklahomensis using new CT data. Areas that were segmented and examined include obscured parts of the lower 101 jaw and palate, the sphenethmoid, the epipterygoids, and elements of the braincase (Fig. 1).

102 Furthermore, the new information obtained from this data also warranted updating the 103 phylogenetic character codings of $F$. oklahomensis, thus updated phylogenetic analyses were 104 performed as well.

105

106 Institutional Abbreviations: OMNH, Sam Noble Oklahoma Museum of Natural History, 107 Norman, Oklahoma, USA.

108

109

110 Materials \& Methods

\section{Specimen}


113 currently only known specimen, OMNH 73541. It was previously studied and described by

114 MacDougall and Reisz (2012).

115

\section{Computed Tomography Data}

The skull of Feeserpeton oklahomensis was scanned using the x-ray computed

118 tomography setup (Phoenix | x-ray Nanotom | s) at the Museum für Naturkunde in Berlin. Scan

119 parameters were set to $57 \mathrm{kV}$ voltage and $170 \mu \mathrm{A}$ current with 1440 images $/ 360^{\circ}$ at an exposure

120 time of $1000 \mathrm{~ms} /$ image and an effective voxel size of $0.0129 \mathrm{~mm}$, resulting in a magnification

121 rate of 3.857. Cone beam reconstruction was performed using datos I x-ray sensing 4 Inspection

122 Technologies GmbH (phoenix I x-ray) with a correction value of 1.845 . The elements were

123 visualized and digitally segmented in VG studio Max 3.2. Smoothing of elements was

124 accomplished by rendering the images using the volume rendering setting 'Phong' with an

125 oversampling of 2.

126

\section{Phylogenetic Analyses}

The data matrix used in the two phylogenetic analyses is based on the data matrix of

129 MacDougall et al. (2018). The analyses were performed in PAUP 4.0a165 (Swofford, 2003),

130 using parsimony as the optimality criterion. The outgroup was set to include the taxa Seymouria,

131 Limnoscelis, and Orobates. Furthermore, minimum branch lengths of zero were set to collapse.

132 For the first analysis a heuristic search (TBR) was performed, with the addition sequence

133 algorithm set to simple, and multistate characters unordered. Both a bootstrap (1000 replicates)

134 and Bremer decay analysis were conducted to determine support values for clades. 
136 Piñeiro (2018) to see how the ordering of characters would affect tree topology and support 137 values.

138 The character codings of Feeserpeton oklahomensis were updated based on new

139 information obtained from the CT data. The characters that were recoded are as follows:

140 interpterygoid vacuity anterior extent (61) $? \rightarrow 0$, alar flange of the vomer presence or absence

141 (64) $? \rightarrow 0$, cultriform process present; (67) $? \rightarrow 1$, pterygoid anterior extent (85) ? $\rightarrow 0$, cultriform

142 process anterior extent $(86) ? \rightarrow 1$, sutural contact between paroccipital process and

143 dermatocranium (92) ? $\rightarrow 1$, Meckelian fossa orientation (108) ? $\rightarrow 0$, Meckelian fossa

144 anteroposterior length (109) ? $\rightarrow 0$, number of coronoids (113) ? $\rightarrow 1$, prearticular anterior extent

145 (114) $1 \rightarrow 0$, coronoid process height (119) ? $\rightarrow 0$, high coronoid process composition (120) ? $\rightarrow-$,

146 single large tooth on anteriormost end of vomer (169) $1 \rightarrow 0$. Furthermore, a few characters were

147 recoded for other taxa to correct some coding errors; these changes are indicated in the data

148 matrix. The updated data matrix and the full character list can be found in the supplementary 149 info.

\section{Description} and obscured areas of the skull to be examined and segmented (Fig. 1). These areas include parts of the palate and the mandible, the sphenethmoid, the epipterygoids, and elements of the

156 braincase. 


\section{The Palate}

159

Many of the palatal elements of Feeserpeton oklahomensis are visible in the holotype;

160 however, only the right side of the palate was prepared, and there are portions of it that are

161 obscured by supportive matrix. Through segmentation of the CT data both sides of the palate are

162 visible in their entirety (Fig. 2), some parts of the palate are damaged or not preserved, but it is

163 largely intact. The most notable feature of the palate that is clarified is the extent of the palatal

164 dentition, in particular on the palatine. The left palatine appears to be largely complete and grants

165 us a view of the element that was not available previously.

166 As was suggested by MacDougall and Reisz (2012), the palatine is a large element and

167 makes up a considerable portion of the overall palatal surface. Anteriorly, the palatine contacts

168 the vomer, whereas it contacts the pterygoid medially and posteriorly, the ectopterygoid is also

169 contacted posteriorly. Laterally, there is a contact with the maxilla. MacDougall and Reisz

170 (2012) note that there are two clusters of palatine teeth visible, though the full extent of these

171 clusters could not be fully determined. The segmented left palatine clearly shows that there is a

172 lateral and medial group of teeth on the element; they are roughly organized in the form of rows.

173 The lateral row consists of seven large teeth and a few smaller ones, whereas the medial row

174 consists of several smaller teeth.

175 The full anteroposterior extent of the vomer is also now apparent, the element is about the

176 same length as the palatine, and ends anteriorly with a narrow, pointed medially positioned

177 process. Likewise, the full lateral extent of the element reveals that the anterior end of the

178 palatine is nestled between two posterior extensions of the vomer: a broad medial extension, and

179 a narrower lateral one. 
181 clear that the interpterygoid vacuity extends quite far anteriorly, past the posterior edge of the

182 palatines. Likewise, it is apparent that the cultriform process of the parasphenoid extends

183 forward for much of the length of the vacuity. Furthermore, the dorsal surface of the

184 parasphenoid is now visible for the first time, revealing several previously unknown aspects of

185 its anatomy. Anteriorly, where the cultriform process merges with the body of the parasphenoid, 186 a small pit, the sella turcica, is visible. Immediately posterior to this pit is the dorsum sellae, a 187 slightly raised wall that borders the sella turcica. Unfortunately, due to the poorer resolution of 188 the CT data in this area, certain features of the parasphenoid were not able to be segmented, 189 specifically the small teeth that are present on this element (MacDougall \& Reisz, 2012).

190 Furthermore, a suborbital foramen is not present, with the palate being unbroken at the 191 intersection of the pterygoid, palatine, and ectopterygoid, as is the case in other lanthanosuchoids 192 (deBraga \& Reisz, 1996; Reisz, MacDougall \& Modesto, 2014).

193

194 The Mandible

195 Due to the mandibular rami of Feeserpeton oklahomensis being occluded with the upper 196 jaw, only details of the ventral and labial surfaces can be clearly observed, with much of the 197 dorsal and lingual surfaces being obscured by the occlusion. However, segmentation of the entire 198 left mandibular ramus (Fig. 3) reveals new information regarding these previously inaccessible 199 areas. The left ramus is slightly damaged on its labial surface, which results in a small gap 200 through which the labial surface of the prearticular can be seen. MacDougall and Reisz (2012) used CT data to investigate the dentition of the dentary,

202 though only the shape of the teeth was examined. The segmented mandibular ramus of the 
203 holotype exhibits 21 teeth on the dentary, however, when empty alveoli are included the total

204 number of dentary teeth increases to 25 . Furthermore, there are enlarged teeth found on the

205 anterior end of the element; there are two visible and an empty alveolus, suggesting that there

206 would have been three enlarged teeth, the same pattern that is observed on the maxilla

207 (MacDougall \& Reisz, 2012).

208 One of the more notable features of the mandible are the coronoid elements (Figs. 3, 4).

209 In their investigation of multiple coronoids and coronoid dentition in Palaeozoic reptiles, the

210 coronoid of Feeserpeton oklahomensis was examined by Haridy et al. (2017) using CT data.

211 They identified the presence of two coronoids on each ramus, as well as the presence of coronoid

212 dentition. We are able to confirm that coronoid dentition is present in F. oklahomensis (Fig. 4),

213 though much of the dentition appears to not be preserved, there are three small teeth that are

214 clearly visible on the right coronoid. However, unlike what was observed by Haridy et al. (2017),

215 we find no trace of two coronoid elements (Fig. 3), suggesting that the presence of multiple

216 coronoids in F. oklahomensis was likely a misinterpretation.

217 The coronoid itself is a relatively long element found lingual to the posterior end of the

218 dentary. It extends anteriorly from its posterior articulation with the surangular to the $18^{\text {th }}$ tooth

219 position of the dentary, narrowing for most of its length. A posteroventral process of the

220 coronoid curves posteriorly to meet with the prearticular.

221 The splenial is largely restricted to the medial surface of the mandibular ramus (Fig. 3),

222 making it difficult to examine fully previously. Anteriorly, the two splenials would have met

223 with another and contributed to the mandibular symphysis. The anterior end of the splenial also

224 exhibits the presence of the foramen intermandibularis oralis. Usually, in early reptiles there was

225 also a foramen intermandibularis caudalis found at the intersection of the splenial, angular, and 
226 prearticular, but it does not appear to be present in this specimen of $F$. oklahomensis, which may

227 be the result of the slight damage present in this area.

228 The full extent of the prearticular, an element not described by MacDougall and Reisz

229 (2012), is revealed in the segmented mandibular ramus (Fig. 3). It is a long element that extends

230 from the articular to the posterior end of the splenial. It also articulates ventrally with the portion

231 of the angular that wraps around to the medial side of the ramus, whereas its anterodorsal edge

232 contacts the coronoid and dentary. The dorsal portion of the prearticular forms the medial margin

233 of the large adductor fossa. Overall, the prearticular is quite similar in shape and position to that

234 of other closely related taxa, such as Delorhynchus (Haridy, MacDougall \& Reisz, 2017).

235 The Meckelian fossa, normally completely obscured by the occlusion of the jaws to the

236 rest of the skull, is revealed in its entirety in the segmented mandibular ramus as well (Fig. 3).

237 The Meckelian fossa of Feeserpeton oklahomensis is found on the posterior end of the

238 mandibular ramus. The fossa faces dorsomedially and it is quite long, extending anteriorly for

239 about a third of the length of the ramus, as is the case in Delorhynchus (Haridy, MacDougall \&

240 Reisz, 2017).

241

242 The Sphenethmoid

243 The sphenethmoid is a rarely described element in early reptiles, usually because it is

244 either not preserved or not visible. Due to the internal position of the sphenethmoid in the

245 holotype of Feeserpeton it was not noted or discussed in MacDougall and Reisz (2012), here we

246 present the fully segmented sphenethmoid element (Fig. 5).

247 The sphenethmoid is found in its expected position, ventral to the frontals. It is a roughly

248 Y-shaped element when viewed in anterior and posterior aspects, possessing a slender ventral 
249 process (often termed the keel) and two equally slender dorsal processes with a rounded trough

250 between them. Lateral view of the element reveals that its anteroposterior length is about

251 equivalent to its dorsoventral height. This sphenethmoid shape is similar to what has been

252 observed in other early reptiles, such as Captorhinus (Heaton, 1979; Modesto \& Reisz, 2008).

253

254 The Epipterygoids

255 The epipterygoids are another example of rarely described elements of early reptiles,

256 largely due to their interior position within the skull. The new CT data reveal the presence of

257 both epipterygoids in the holotype of Feeserpeton oklahomensis, which were both fully

258 segmented for the purpose of this study (Fig. 6). These elements were not described by

259 MacDougall and Reisz (2012) as they are not exposed externally. Both epipterygoids appear to

260 be disarticulated and not in their natural positions (Fig. 1), but overall they are similar in

261 structure to those that have been described for other early reptiles (Romer, 1956; Carroll \&

262 Lindsay, 1985), possessing a gracile dorsal columella that arches slightly posterior, and a ventral

263 region that expands to form a more robust footplate with a broad anteroposterior length. The

264 footplate also exhibits a process on its anteromedial surface, a characteristic that has also been

265 observed in other early reptiles, such as Captorhinus (Fox \& Bowman, 1966). In their natural

266 positions the dorsal columella of each epipterygoid would have contacted the supraoccipital and

267 prootic, whereas the footplate would have presumably met with the quadrate process of the

268 pterygoid, as is the case in Captorhinus (Fox \& Bowman, 1966) and the procolophonids

269 Leptopleuron and Hypsognathus (Sues et al., 2000; Cisneros, 2008).

270

271 The Braincase

Peer) reviewing PDF | (2019:04:37076:2:0:NEW 20 Aug 2019) 
273 Reisz (2012), however, there was still substantial portions of its overall anatomy that could not

274 be described due to being obscured. The fully segmented braincase presented here (Fig. 7)

275 reveals several details that could not be observed in the original description of the holotype. It is

276 also quite apparent that the braincase exhibits slight disarticulation of elements from their natural

277 position, as well as some damaged areas.

278 The prootics of Feeserpeton are large, irregularly shaped anterior elements of the

279 braincase and form an extensive portion of its overall structure. While MacDougall and Reisz

280 (2012) were able to identify the prootics, they were only able to describe the exposed ventral

281 surface of the elements, which is only a small portion of the overall element. The prootics appear

282 to be entirely intact but are slightly disarticulated and not in contact with most of the other

283 elements of the braincase, though laterally they do have a slight contact with their respective

284 opisthotics. The posterior surface of the prootic would have articulated with the anterior surface

285 of the opisthotic. The flattened posterolateral extension of the element, usually termed the

286 paroccipital process of the prootic would have met with the paroccipital process of the opisthotic,

287 with a large depression in this region of the prootic contributing to the fenestra ovalis.

288 Dorsomedially, there is a small process that would have met with the supraoccipital. The medial

289 portion of the element exhibits another smaller process that extends ventrally out from the main

290 body of the prootic, which would likely have come close to contacting the basioccipital. The

291 anterior part of the prootic is convex in shape. Overall, the structure of the prootic is largely

292 similar to what has been described for other parareptiles, such as Leptopleuron (Spencer, 2000),

293 though in the case of Leptopleuron the prootic appears to be not quite as robust as that of 
294 Feeserpeton. Unfortunately, this is a rarely described element of closely related taxa, due to its 295 often-inaccessible position.

296 The opisthotics are another large component of the braincase, and like the prootics, they

297 were also only partially described by MacDougall and Reisz (2012). The segmented braincase 298 clearly illustrates that both of the opisthotics suffer from damage (Fig. 7), however, the left 299 opisthotic is substantially more damaged than the right one, with a large posterior segment of the 300 element being completely absent. The better preserved right opisthotic clearly exhibits a laterally 301 expanded anterodorsal end, and a posterior portion that extends ventrally. The broad anterior end 302 contributes to the paroccipital process of the opisthotic, which would have met with the 303 paroccipital process of the prootics. Moving medially the posterior portion of the opisthotic 304 expands dorsoventrally and meets with the lateral edge of the fused exoccipital-basioccipital 305 complex, contributing to the posterior end of the braincase and forming the remaining portion of 306 the paroccipital process.

307 The stapes was briefly described by (MacDougall \& Reisz, 2012), and we expand upon 308 their description here. The stapes of Feeserpeton is not in its natural position, being slightly 309 disarticulated; it consists of a bifurcating laterally compressed distal end, and the broad 310 proximally located footplate, which are connected by a short, slightly twisted shaft. In its natural 311 position the footplate would have met with the fenestra ovalis of the paraoccipital process, with 312 the distal end extending laterally towards the quadrate. The distal end of the stapes bifurcates 313 into two distinct processes, the distal facing columella, which appears to be broken, and prior to 314 this process a dorsal extension. The stapes is similar in size and structure to the stapes of 315 Acleistorhinus pteroticus (deBraga \& Reisz, 1996), but is quite distinct from the small gracile 316 stapes of Leptopleuron lacertinum (Spencer, 2000). 


\section{Phylogenetic Analyses}

The first phylogenetic analysis produced 27 optimal trees, each with a tree length of 667.

321 As in the original MacDougall and Reisz (2012) study, the strict consensus tree (Fig. 8) produced

322 from the optimal trees has Feeserpeton oklahomensis being recovered as the sister taxon of all

323 other lanthanosuchoids (it is in this position in all 27 of the optimal trees). The clade

324 Lanthanosuchoidea is recovered as the sister taxon to the clade that contains Bolosauria,

325 Procolophonoidea, Pareiasauridae, Nycteroleteridae, Nyctiphruretidae, and Microleter. This is 326 similar to what was recovered in the analysis of MacDougall and Reisz (2012), except for the 327 inclusion of Microleter within this clade. However, the position of Bolosauria in our analysis 328 differs from what was recovered by other studies (Modesto et al., 2015; MacDougall et al., 329 2017a), where the clade was found to be more basal than Lanthanosuchoidea.

Similar to the results of MacDougall et al. (2018), the ophiacodontid (Archaeothyris) and varanopid taxa (Archaeovenator, Mycterosaurus) included in the analysis were recovered as

332 being more closely related to the reptile taxa than to the synapsids. This is an atypical result that 333 warrants further investigation in the future, but is at least partly in line with the results of recent 334 work that has recovered varanopids within Reptilia (Ford \& Benson, 2018). In the case of our 335 study this result could potentially be the result of the relatively narrow focus of our analysis. The second analysis in which characters were ordered following the methodology of

337 Laurin \& Piñeiro (2018) produced 9 optimal trees, the consensus of which resulted in a very 338 similar tree (Fig. S1) to that recovered in our first analysis. The only difference being the 
339 resolution of the polytomy that contained the nyctiphruretids, procolophonoids, pareiasaurs, and 340 nycteroleters.

\section{Discussion}

\section{New Information from CT Data}

The early Permian Richards Spur locality has produced a considerable amount of well-

345 preserved fossil material, largely due to the unique preservational environment associated with

346 the caves found there (MacDougall et al., 2017b). In particular near complete skulls are not

347 uncommon at the locality, with many taxa being known almost solely from skulls (e.g. Modesto

348 and Reisz, 2008; Anderson et al., 2009; Tsuji et al., 2010; Polley and Reisz, 2011; MacDougall

349 et al., 2017b). These various well-preserved specimens provide substantial information regarding

350 the anatomy of the taxa to which they belong, however, there are also various regions of these

351 skulls that cannot be examined normally, either due to being obscured or not being exposed

352 externally. CT data are proving to be an ideal way to study these skulls and their difficult to

353 examine areas, which will in turn provide more information regarding the Richards Spur

354 assemblage and the taxa that compose it. The new CT data of the holotype of Feeserpeton

355 oklahomensis have allowed for the segmentation of several previously inaccessible areas,

356 revealing more details regarding the anatomy of this taxon. Specifically, the dentition of the

357 mandible and palate, and various elements of the skull that are largely internal.

358 Recently, there have been other parareptile taxa that have been examined using CT data

359 (Tsuji, Sobral \& Müller, 2013; Zaher, Coram \& Benton, 2018), which resulted in the discovery

360 of new information about the examined taxa, however, there are still numerous parareptile taxa

361 that have yet to be examined in comparable detail using CT scanning. The new information that 
362 will be obtained from examining other parareptiles using CT scans will be important for

363 resolving issues and testing existing hypotheses regarding early amniote relationships (Laurin \&

364 Piñeiro, 2017, 2018; Ford \& Benson, 2018; MacDougall et al., 2018), as well as for better

365 understanding the anatomy and evolution of these taxa (Zaher, Coram \& Benton, 2018).

366

367 The Coronoid Eminence of Feeserpeton

368 One of the aspects of the anatomy of Feeserpeton oklahomensis that was clarified with

369 CT data is the composition of the coronoid eminence. The coronoid eminence of

370 lanthanosuchoids has been shown to be quite complex, with the presence of multiple coronoids

371 and dentition present on the elements (Haridy, MacDougall \& Reisz, 2017; MacDougall et al.,

372 2017a). Our identification of a single coronoid on the mandibular ramus of F. oklahomensis (Fig.

373 3), which is contrary to the observations of Haridy et al. (2017), does not dramatically change

374 their interpretations about the evolution of the trait within Lanthanosuchoidea. The only potential

375 change this reinterpretation introduces to their hypothesis is that the presence of multiple

376 coronoids does not appear to be primitive for Lanthanosuchoidea, instead appearing later in the

377 evolution of the clade. However, we were able to confirm that the coronoid of $F$. oklahomensis

378 does indeed exhibit dentition (Fig. 4), thus it is clear that denticulate coronoids are the primitive

379 condition for lanthanosuchoids, as was hypothesized by Haridy et al. (2017). Other

380 lanthanosuchoid taxa, notably Acleistorhinus pteroticus, will have to be reexamined in the future

381 to further elucidate details regarding the evolution of multiple and denticulate coronoids within

382 the clade. 
385 Conclusions

386 Through computed tomography data and modern visualization techniques this study

387 reveals new information regarding the anatomy of the early Permian reptile Feeserpeton

388 oklahomensis. Notably, we were able to describe numerous details regarding the anatomy of the

389 mandibular rami, the palate, the sphenethmoid, the epipterygoids, and the braincase. All of which

390 are parts of the skull that cannot be fully examined normally in the holotype specimen. This new

391 information also allowed for several previously unknown phylogenetic characters to be coded.

392 The evolution and relationships of early amniotes is still an area of palaeontological research that

393 is far from set in stone, and the investigation of normally inaccessible anatomy using CT data has

394 been and will continue to be important for better understanding reptile, and more broadly, early

395 tetrapod evolution.

396

397

398 Acknowledgements

399 We would like to thank the Richard Cifelli and William May, for their assistance in

400 acquiring this and other specimens, we also thank Mike Feese for his assistance, and his donating

401 of many Richards Spur specimens to the OMNH. We also thank Sean Modesto, Michel Laurin,

402 and Juan Cisneros for reviewing the manuscript and providing very helpful comments. Mark J.

403 MacDougall was supported by a Leibniz-DAAD postdoctoral scholarship and currently a

404 Humboldt postdoctoral fellowship, Jasper Ponstein is supported by a Research Track Scholarship

405 of the Humboldt-Universität zu Berlin within the Excellence initiative of the states and the

406 federal government, Robert R. Reisz is supported by a National Science and Engineering 
407 Research Council (NSERC) Discovery grant, and Jörg Fröbisch is supported by the German 408 Research Foundation (DFG).

409

410

\section{References}

412 Anderson JS, Scott D, Reisz RR. 2009. Nannaroter mckinziei, a new ostodolepid 'microsaur' 413 (Tetrapoda, Lepospondyli, Recumbirostra) from the Early Permian of Richards Spur (Ft. Sill), Oklahoma. Journal of Vertebrate Paleontology 29:379-388. DOI: 10.1671/039.029.0222.

Carroll RL, Lindsay W. 1985. Cranial anatomy of the primitive reptile Procolophon. Canadian Journal of Earth Sciences 22:1571-1587. DOI: 10.1139/e85-166.

Cisneros JC. 2008. Phylogenetic relationships of procolophonid parareptiles with remarks on their geological record. Journal of Systematic Palaeontology 6:345-366. DOI: $10.1017 /$ S1477201907002350.

421

422

423

424

425

426

deBraga M, Reisz RR. 1996. The Early Permian reptile Acleistorhinus pteroticus and its phylogenetic position. Journal of Vertebrate Paleontology 16:384-395. DOI: 10.1080/02724634.1996.10011328.

Ford DP, Benson RBJ. 2018. A redescription of Orovenator mayorum (Sauropsida, Diapsida) using high-resolution $\mu \mathrm{CT}$, and the consequences for early amniote phylogeny. Palaeontology.

Fox RC. 1962. Two new pelycosaurs from the Lower Permian of Oklahoma. University of Kansas Publications of the Museum of Natural History 12:297-307. 
429 Fox RC, Bowman MC. 1966. Osteology and relationships of Captorhinus aguti (Cope)

430 (Reptilia: Captorhinomorpha). The University of Kansas Paleontological

431 Contributions 11:1-79.

432 Haridy Y, MacDougall MJ, Reisz RR. 2017. The lower jaw of the Early Permian parareptile

433

434

435

436

437

438

439

440

441

442

443

444

445

446

447

448

449

450
Delorhynchus, first evidence of multiple denticulate coronoids in a reptile. Zoological Journal of the Linnean Society. DOI: 10.1093/zoolinnean/zlx085.

Heaton MJ. 1979. Cranial anatomy of primitive captorhinid reptiles from the Late Pennsylvanian and Early Permian, Oklahoma and Texas. Oklahoma Geological Survey Circular 127:84.

Laurin M, Piñeiro GH. 2017. A reassessment of the taxonomic position of mesosaurs, and a surprising phylogeny of early amniotes. Frontiers in Earth Science 5. DOI: 10.3389/feart.2017.00088.

Laurin M, Piñeiro G. 2018. Response: commentary: a reassessment of the taxonomic position of mesosaurs, and a surprising phylogeny of early amniotes. Frontiers in Earth Science 6. DOI: 10.3389/feart.2018.00220.

MacDougall MJ, Modesto SP, Brocklehurst N, Verrière A, Reisz RR, Fröbisch J. 2018. Commentary: a reassessment of the taxonomic position of mesosaurs, and a surprising phylogeny of early amniotes. Frontiers in Earth Science 6. DOI: 10.3389/feart.2018.00099.

MacDougall MJ, Modesto SP, Reisz RR. 2016. A new reptile from the Richards Spur locality, Oklahoma, U.S.A., and patterns of Early Permian parareptile diversification. Journal of Vertebrate Paleontology 36:e1179641. DOI: 10.1080/02724634.2016.1179641. 
451 MacDougall MJ, Reisz R. 2012. A new parareptile (Parareptilia, Lanthanosuchoidea) from 452 453 the Early Permian of Oklahoma. Journal of Vertebrate Paleontology 32:1018-1026. DOI: $10.1080 / 02724634.2012 .679757$.

454 MacDougall MJ, Reisz RR. 2014. The first record of a nyctiphruretid parareptile from the 455 456 457 458 459

460

461

462

463

464

465

466

467

468 Early Permian of North America, with a discussion of parareptilian temporal fenestration. Zoological Journal of the Linnean Society 172:616-630. DOI: 10.1111/zoj.12180.

MacDougall MJ, Scott D, Modesto SP, Williams SA, Reisz RR. 2017a. New material of the reptile Colobomycter pholeter (Parareptilia: Lanthanosuchoidea) and the diversity of reptiles during the Early Permian (Cisuralian). Zoological Journal of the Linnean Society 180:661-671. DOI: 10.1093/zoolinnean/zlw012.

MacDougall MJ, Tabor NJ, Woodhead J, Daoust AR, Reisz RR. 2017b. The unique preservational environment of the Early Permian (Cisuralian) fossiliferous cave deposits of the Richards Spur locality, Oklahoma. Palaeogeography, Palaeoclimatology, Palaeoecology 475:1-11.

Modesto SP. 1999. Colobomycter pholeter from the Lower Permian of Oklahoma: a parareptile, not a protorothyridid. Journal of Vertebrate Paleontology 19:466-472. DOI: 10.1080/02724634.1999.10011159.

Modesto SP, Reisz RR. 2008. New material of Colobomycter pholeter, a small parareptile 470 from the Lower Permian of Oklahoma. Journal of Vertebrate Paleontology 28:677684. DOI: 10.1671/0272-4634(2008)28[677:NMOCPA]2.0.CO;2. 
472 Modesto SP, Scott DM, MacDougall MJ, Sues H-D, Evans DC, Reisz RR. 2015. The oldest

473 parareptile and the early diversification of reptiles. Proceedings of the Royal Society

$474 \quad$ of London B: Biological Sciences 282:20141912. DOI: 10.1098/rspb.2014.1912.

475 Modesto SP, Scott DM, Reisz RR. 2009. Arthropod remains in the oral cavities of fossil

476 reptiles support inference of early insectivory. Biology Letters 5:838-840. DOI:

477 10.1098/rsbl.2009.0326.

478 Polley BP, Reisz RR. 2011. A new Lower Permian trematopid (Temnospondyli:

479 Dissorophoidea) from Richards Spur, Oklahoma. Zoological Journal of the Linnean 480 Society 161:789-815. DOI: 10.1111/j.1096-3642.2010.00668.x.

481 482 483 484 485 486 487 488 489 490 491 492 493 494

Reisz RR. 1997. The origin and early evolutionary history of amniotes. Trends in Ecology \& Evolution 12:218-222. DOI: 10.1016/S0169-5347(97)01060-4.

Reisz RR, Barkas V, Scott D. 2002. A new early Permian bolosaurid reptile from the Richards Spur Dolese Brothers Quarry, near Fort Sill, Oklahoma. Journal of Vertebrate Paleontology 22:23-28. DOI: 10.1671/02724634(2002)022[0023:ANEPBR]2.0.CO;2.

Reisz RR, MacDougall MJ, Modesto SP. 2014. A new species of the parareptile genus Delorhynchus, based on articulated skeletal remains from Richards Spur, Lower Permian of Oklahoma. Journal of Vertebrate Paleontology 34:1033-1043. DOI: $10.1080 / 02724634.2013 .829844$.

Romer AS. 1956. Osteology of the Reptiles. Chicago: The University of Chicago Press. Sennikov AG. 1996. Evolution of the Permian and Triassic tetrapod communities of Eastern Europe. Palaeogeography, Palaeoclimatology, Palaeoecology 120:331-351. DOI: 10.1016/0031-0182(95)00041-0. 
495 Spencer PS. 2000. The braincase structure of Leptopleuron lacertinum Owen (Parareptilia:

496 Procolophonidae). Journal of Vertebrate Paleontology 20:21-30. DOI:

497 10.1671/0272-4634(2000)020[0021:TBSOLL]2.0.CO;2.

498

499

500

501

502

503

504

505

506

507

508

509

510

511

512

513

514

515

516 a latest Triassic procolophonid reptile from the Newark Supergroup of eastern North America. Journal of Vertebrate Paleontology 20:275-284. DOI: 10.1671/02724634(2000)020[0275:COOHFA]2.0.CO;2.

Sullivan C, Reisz RR. 1999. First record of Seymouria (Vertebrata: Seymouriamorpha) from Early Permian fissure fills at Richards Spur, Oklahoma. Canadian Journal of Earth Sciences 36:1257-1266. DOI: 10.1139/e99-035.

Swofford DL. 2003. PAUP*. Phylogentic Analysis Using Parsimony (*and Other Methods). Sunderland, Massachusetts: Sinauer Associates.

Tsuji LA, Müller J, Reisz RR. 2010. Microleter mckinzieorum gen. et sp. nov. from the Lower Permian of Oklahoma: the basalmost parareptile from Laurasia. Journal of Systematic Palaeontology 8:245-255. DOI: 10.1080/14772010903461099.

Tsuji LA, Sobral G, Müller J. 2013. Ruhuhuaria reiszi, a new procolophonoid reptile from the Triassic Basin of Tanzania. Comptes Rendus Palevol 12:487-494.

Vaughn PP. 1958. On a new pelycosaur from the lower Permian of Oklahoma, and on the origin of the family Caseidae. Journal of Paleontology 32:981-991.

Verrière A, Brocklehurst N, Fröbisch J. 2016. Assessing the completeness of the fossil record: comparison of different methods applied to parareptilian tetrapods (Vertebrata: Sauropsida). Paleobiology 42:680-695. DOI: 10.1017/pab.2016.26. 
517 Zaher M, Coram RA, Benton MJ. 2018. The Middle Triassic procolophonid Kapes bentoni:

518 computed tomography of the skull and skeleton. Papers in Palaeontology 5:111-138.

$519 \quad$ DOI: $10.1002 / \operatorname{spp} 2.1232$.

520

521

522 Figure Captions

523 Figure 1. The skull of Feeserpeton oklahomensis, OMNH 73541, showing the regions that were

524 reconstructed using CT data. Scale bar equals $2 \mathrm{~mm}$. [Half page width]

525

526 Figure 2. The palate of Feeserpeton oklahomensis, OMNH 73541, reconstructed from CT data.

527 A, dorsal view, and $\mathbf{B}$, ventral view. Abbreviations: ec, ectopterygoid; m, maxilla; pal, palatine;

528 ps, parasphenoid; pt, pterygoid; $\mathbf{v}$, vomer. Scale bar equals $4 \mathrm{~mm}$. [Half page width]

529

530 Figure 3. The left mandibular ramus of Feeserpeton oklahomensis, OMNH 73541, reconstructed

531 from CT data. A, dorsal view, B, ventral view, $\mathbf{C}$, labial view, and $\mathbf{D}$, lingual view.

532 Abbreviations: an, angular; ar, articular; c, coronoid; d, dentary; pra, prearticular; sa,

533 surangular; sp, splenial. Scale bar equals $2 \mathrm{~mm}$. [Half page width]

534

535 Figure 4. The right coronoid of Feeserpeton oklahomensis, OMNH 73541, reconstructed from

536 CT data. A, lingual view, and $\mathbf{B}$, dorsal view. Scale bar equals $1 \mathrm{~mm}$. [Half page width]

537 
538 Figure 5. The sphenethmoid of Feeserpeton oklahomensis, OMNH 73541, reconstructed from

539 CT data. A, anterior view, B, posterior view, C, dorsal view, and D, right lateral view. Scale bar 540 equals $1 \mathrm{~mm}$. [Half page width]

541

542 Figure 6. The left epipterygoid of Feeserpeton oklahomensis, OMNH 73541, reconstructed from

543 CT data. A, lateral view, B, medial view, C, dorsal view, and D, ventral view. Scale bar equals 1

$544 \mathrm{~mm}$. [Half page width]

545

546 Figure 7. The braincase of Feeserpeton oklahomensis, OMNH 73541, reconstructed from CT

547 data. A, dorsal view, B, ventral view, C, right lateral view, and D, posterior view. Abbreviations:

548 bo, basioccipital; eo, exoccipitals; op, opisthotic; pro, prootic; ps, parasphenoid; so,

549 supraoccipital; st, stapes; ?, unknown fragment that may be part of the left stapes or the left

550 opisthotic. Scale bar equals $2 \mathrm{~mm}$. [Half page width]

551

552 Figure 8. Strict consensus tree obtained from the first phylogenetic analysis, where characters 553 were unordered. Tree length $=667$, consistency index $=0.301$, rescaled consistency index $=$ 5540.195 , retention index $=0.647$. Nodes of clades of interest are labeled: A, Amniota; B, Reptilia;

555 C, Parareptilia; D, Eureptilia; E, Lanthanosuchoidea; F, Bolosauria; G, Nyctiphruretidae; H, 556 Nycteroleteridae; I, Pareiasauridae; J, Procolophonoidea. Bootstrap support values are found 557 above nodes, if no value is indicated it was less than $50 \%$. Bremer support values are found 558 below nodes, if no value is indicated the clade collapsed with the addition of one extra step. 559 [Half page width] 


\section{Figure 1}

The skull of Feeserpeton oklahomensis, OMNH 73541,showing the regions that were reconstructed using $\mathrm{CT}$ data.

Scale bar equals $2 \mathrm{~mm}$.

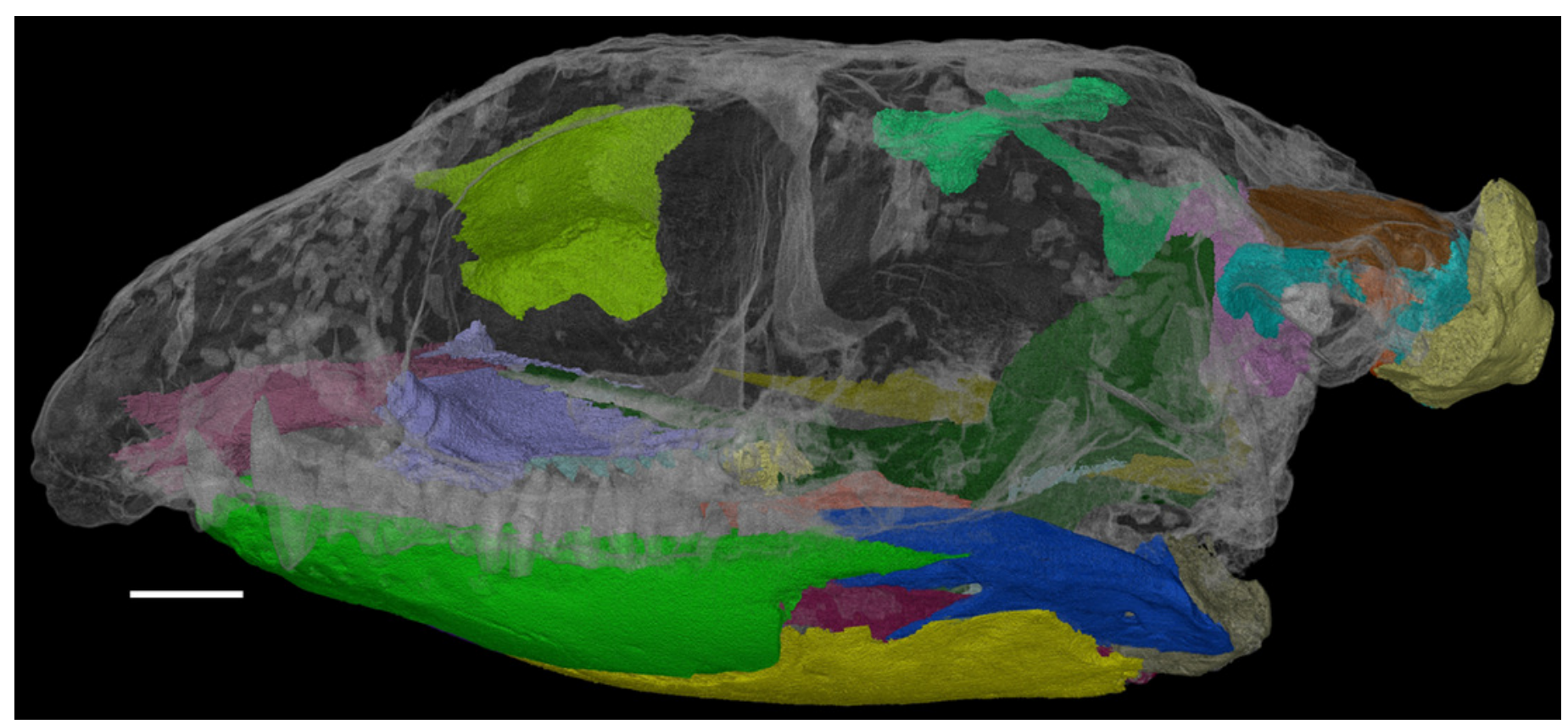


Figure 2

The palate of Feeserpeton oklahomensis, OMNH 73541, reconstructed from CT data.

A, dorsal view, and B, ventral view. Abbreviations: ec, ectopterygoid; m, maxilla; pal, palatine; ps, parasphenoid; pt, pterygoid; $\mathbf{v}$, vomer. Scale bar equals $4 \mathrm{~mm}$. 


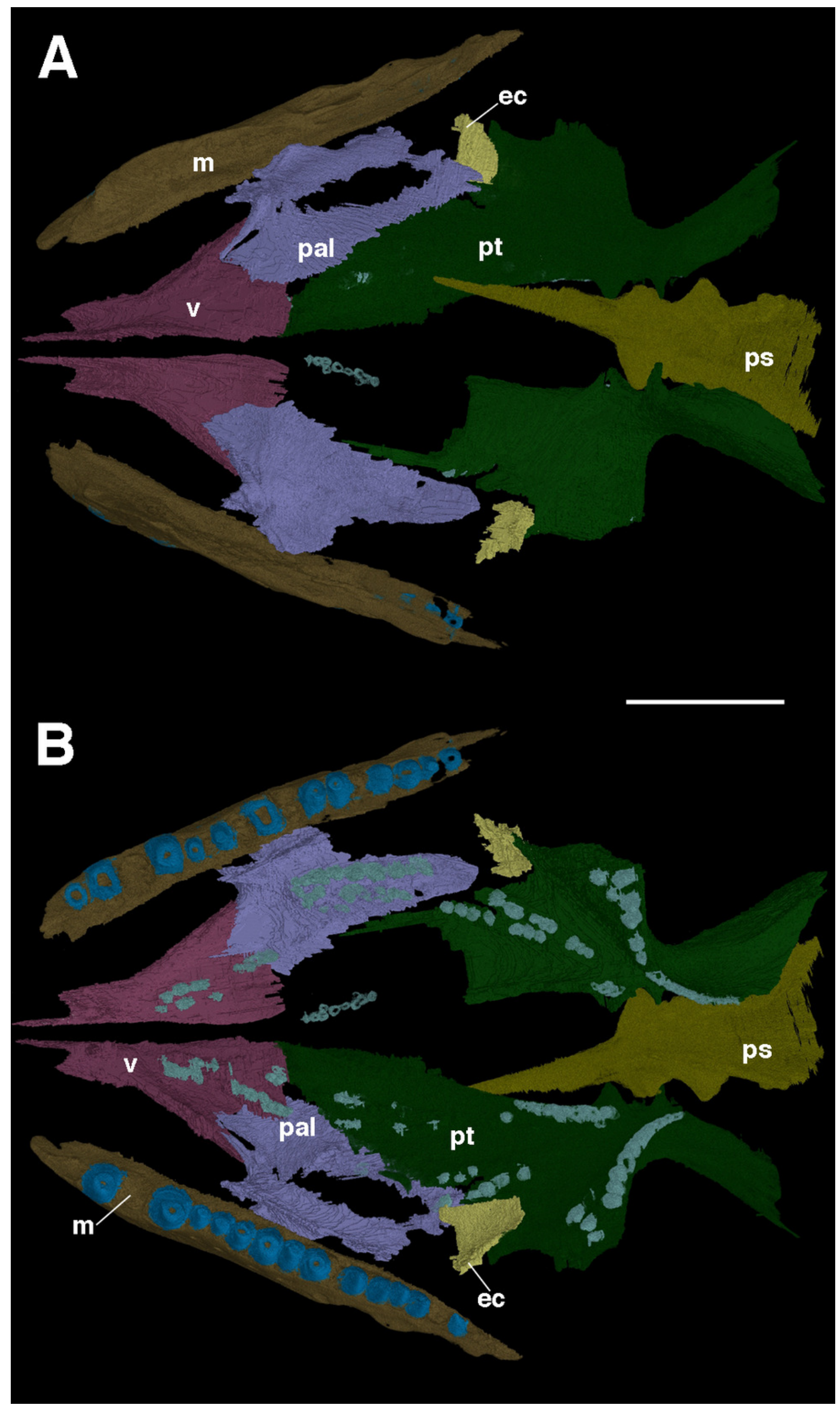

Peer] reviewing PDF | (2019:04:37076:2:0:NEW 20 Aug 2019) 
Figure 3

The left mandibular ramus of Feeserpeton oklahomensis, OMNH 73541,reconstructed from CT data.

A, dorsal view, B, ventral view, C, labial view, andD, lingual view. Abbreviations: an, angular; ar, articular; c, coronoid;d, dentary; pra, prearticular; sa, surangular;sp, splenial. Scale bar equals $2 \mathrm{~mm}$. 


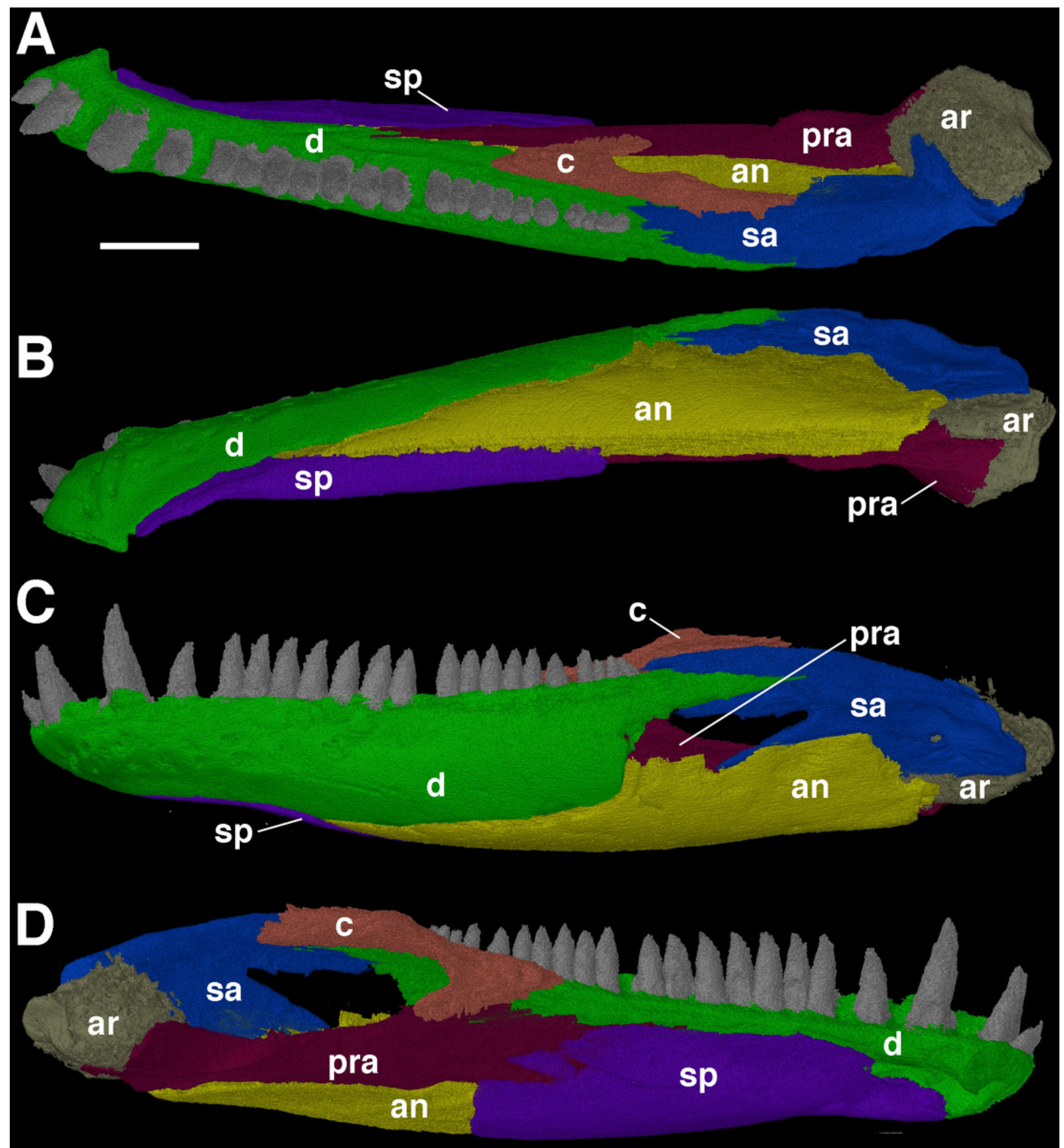




\section{Figure 4}

The right coronoid of Feeserpeton oklahomensis, OMNH 73541, reconstructed from CT data.

A, lingual view, and $\mathbf{B}$, dorsal view. Scale bar equals $1 \mathrm{~mm}$.

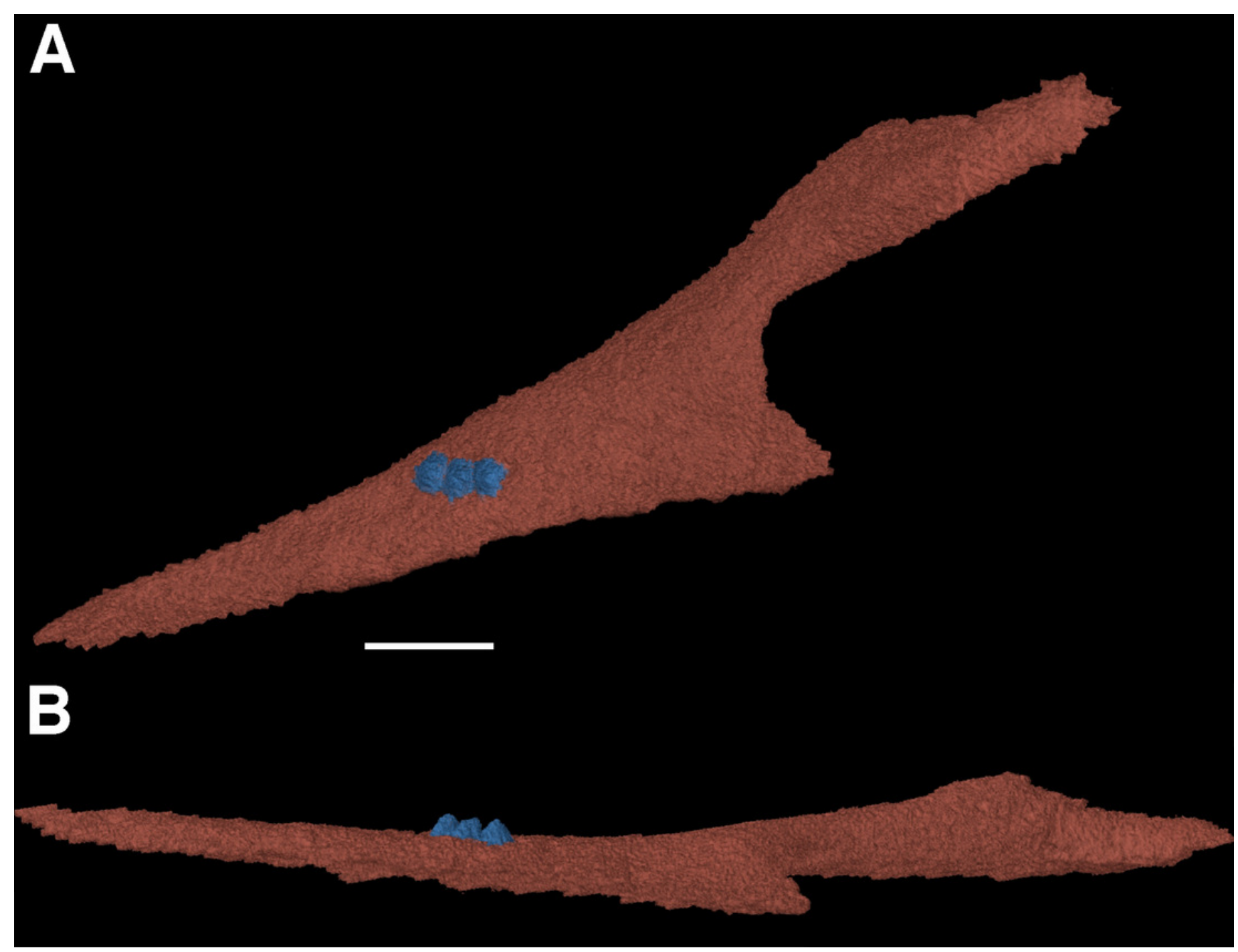




\section{Figure 5}

The sphenethmoid of Feeserpeton oklahomensis, OMNH 7354, reconstructed from CT data.

A, anterior view, B, posterior view, C, dorsal view, and D, right lateral view. Scale bar equals

$1 \mathrm{~mm}$.

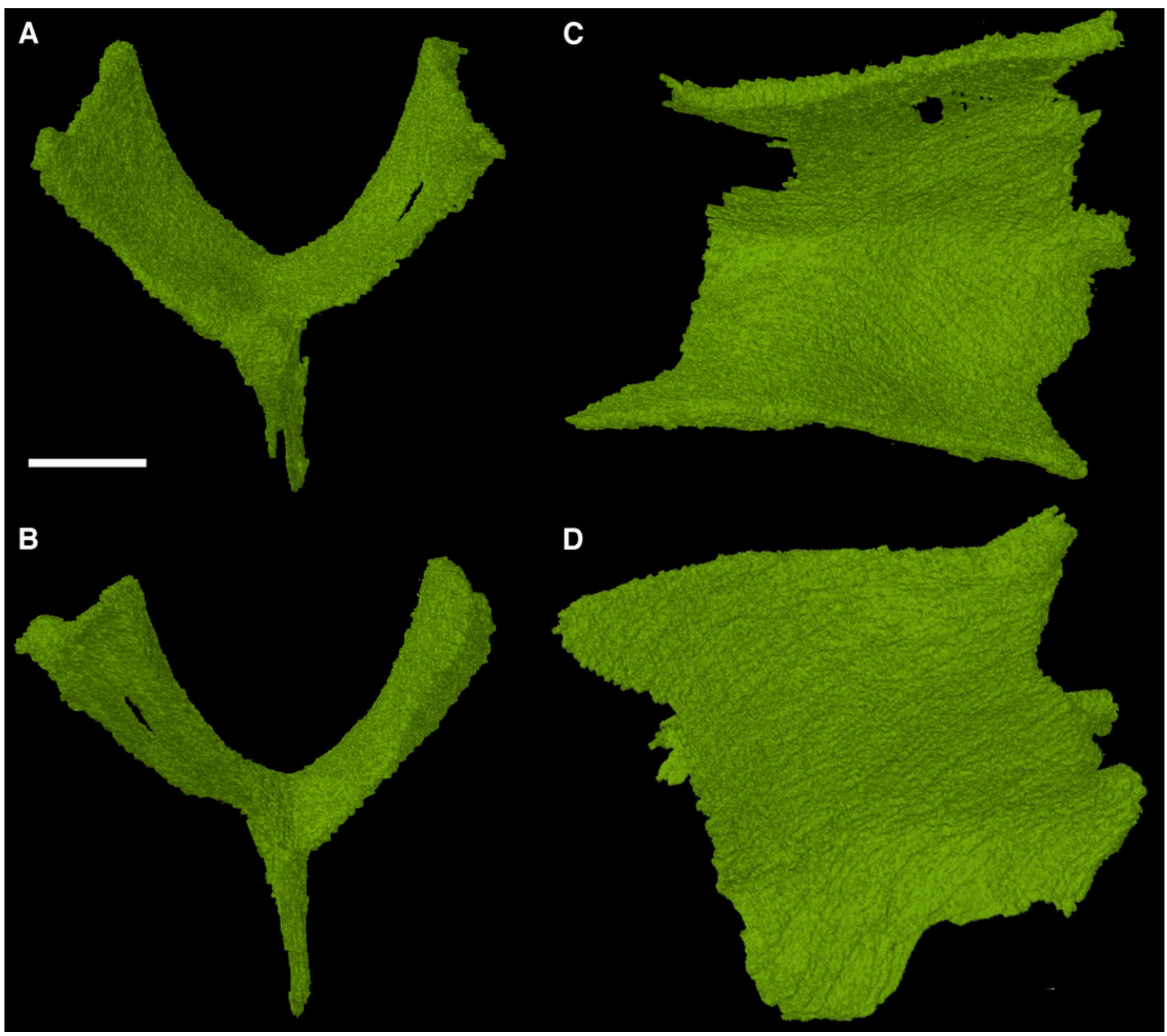


Figure 6

The left epipterygoid of Feeserpeton oklahomensis, OMNH 73541, reconstructed from CT data.

A, lateral view, B, medial view, C, dorsal view, and $\mathbf{D}$, ventral view. Scale bar equals $1 \mathrm{~mm}$. 


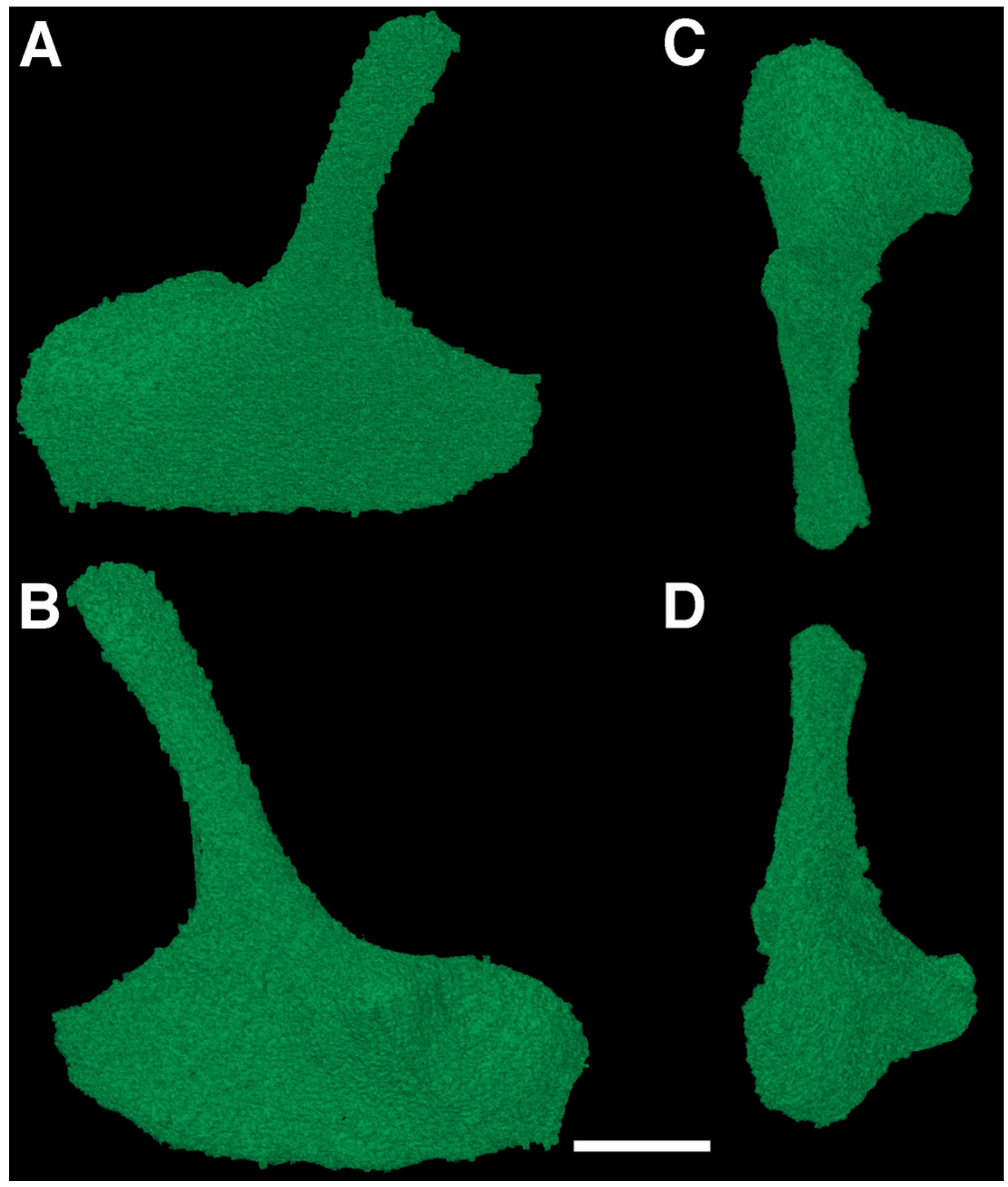




\section{Figure 7}

The braincase of Feeserpeton oklahomensis, OMNH 73541, reconstructed from CT data.

A, dorsal view, B, ventral view, C, right lateral view, and D, posterior view. Abbreviations: bo, basioccipital; eo, exoccipitals; op, opisthotic; pro, prootic;ps, parasphenoid; so,

supraoccipitalst, stapes; ?, unknown fragment that may be part of the left stapes or the left opisthotic. Scale bar equals $2 \mathrm{~mm}$.

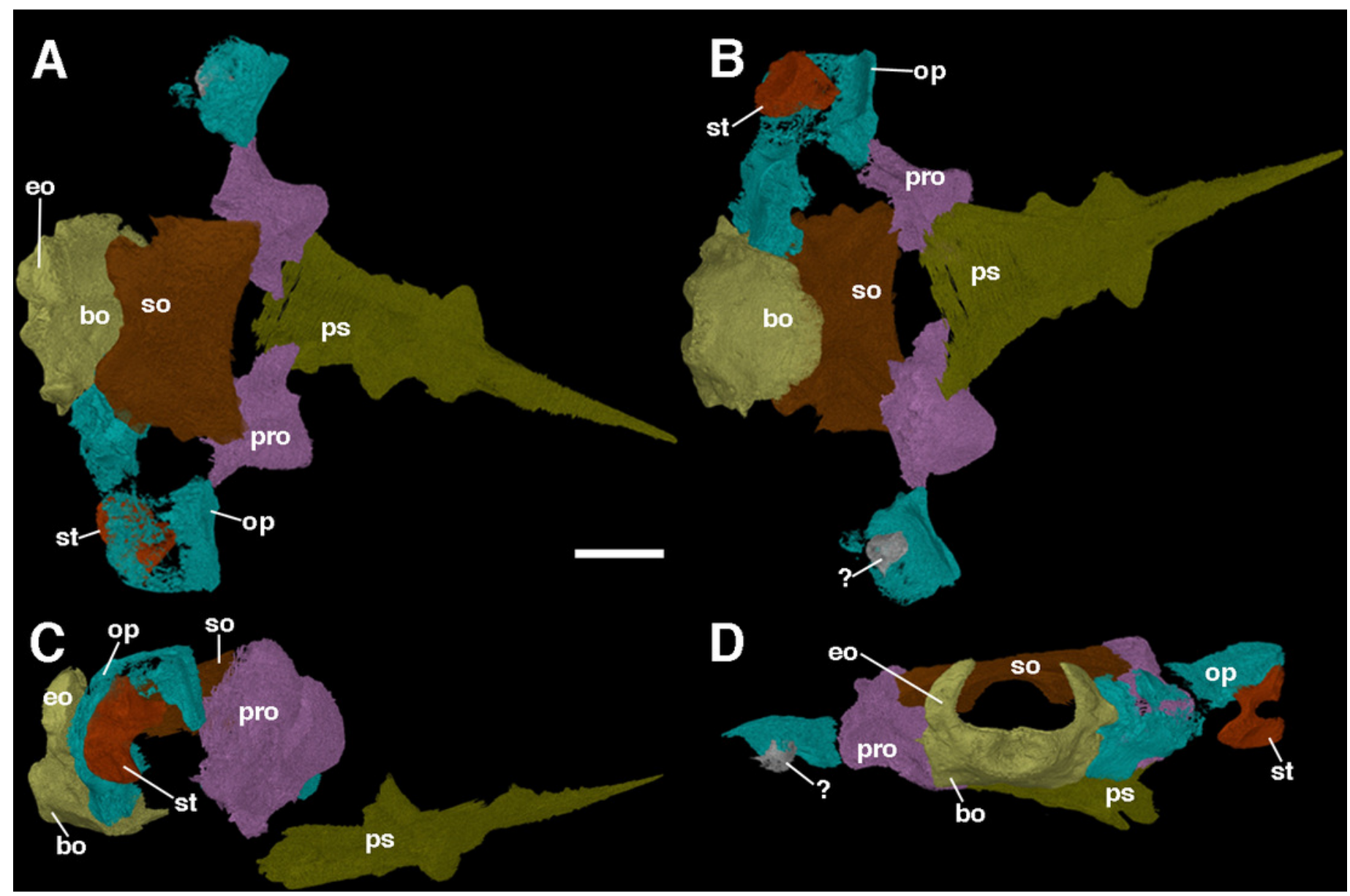




\section{Figure 8}

Strict consensus tree obtained from the phylogenetic analysis.

Tree length $=667$, consistency index $=0.301$, rescaled consistency index $=0.195$, retention index $=0.647$. Nodes of clades of interest are labeled: A, Amniota; B, Reptilia; C, Parareptilia; D, Eureptilia; E, Lanthanosuchoidea; F, Bolosauria; G, Nyctiphruretidae; H, Nycteroleteridae; I, Pareiasauridae; J, Procolophonoidea. Bootstrap support values are found above nodes, if no value is indicated it was less than $50 \%$. Bremer support values are found below nodes, if no value is indicated the clade collapsed with the addition of one extra step. 


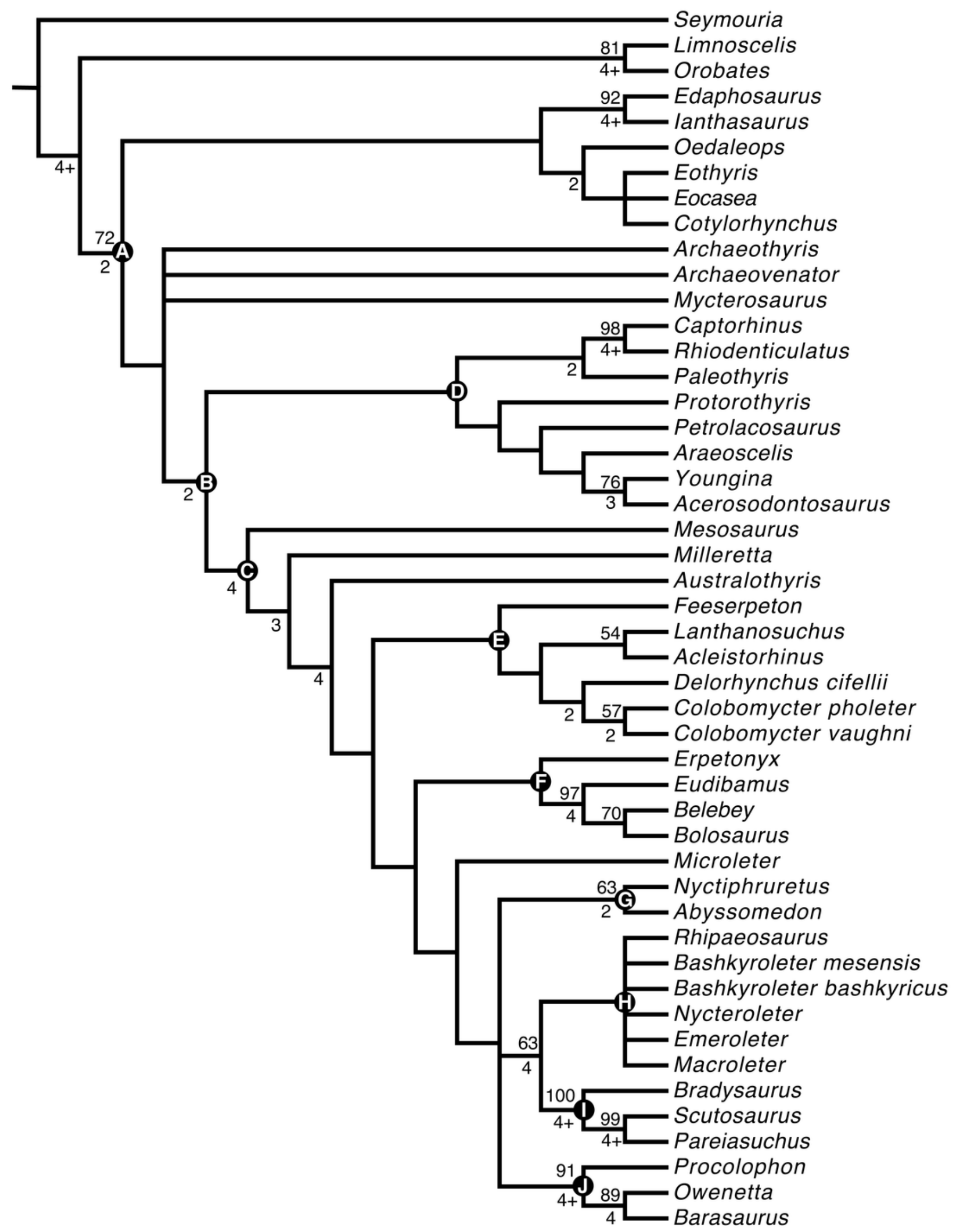

